\title{
Semantic priming in multiple sclerosis
}

\author{
WILLIAM W. BEATTY \\ Neuropsychiatric Research Institute, Fargo, North Dakota \\ and North Dakota State University, Fargo, North Dakota \\ and \\ NANCY MONSON \\ Neuropsychiatric Research Institute, Fargo, North Dakota
}

\begin{abstract}
Previous studies have demonstrated that some patients with multiple sclerosis (MS) exhibit a broad spectrum of deficits in access to lexical and semantic information, including impairments on verbal fluency tasks and naming objects portrayed in line drawings. In an effort to characterize the naming disturbance in MS, a semantic priming task, previously shown to be sensitive to deficits in patients with Alzheimer's disease or Huntington's disease, was employed. Regardless of their performance on tests of global mental status or naming, the MS patients showed normal performance on the semantic priming task. Since a previous study had shown normal performance by MS patients on a test of lexical priming, the difficulties these patients experience gaining access to lexical knowledge appear to reflect retrieval failures rather than a breakdown in the structure of lexical memory.
\end{abstract}

It is widely recognized that deficits in memory and problem solving are frequently observed in patients with multiple sclerosis (MS), but most researchers have believed that language remains intact in this disease (Rao, 1986). However, recent studies (Beatty, Goodkin, Monson, \& Beatty, 1989; Beatty, Goodkin, Monson, Beatty, \& Hertsgaard, 1988; Caine, Bamford, Schiffer, Shoulson, \& Levy, 1986) demonstrating marked impairments on verbal fluency tasks and deficits in naming objects portrayed in line drawings in some patients challenge this view. Although MS patients' difficulties on verbal fluency tasks might be attributed to their inability to process information quickly-a common cognitive symptom of their disease (Beatty, Goodkin, Monson, \& Beatty, 1989; Beatty et al., 1988; Litvan, Grafman, Vendrell, \& Martinez, 1988; Rao, St. Aubin-Faubert, \& Leo, 1989)-it is not clear that dysnomia in MS can be accounted for in this way, since adequate time (usually $20 \mathrm{sec}$ ) is generally allowed for responding on tests of confrontation naming.

Using the Boston Naming Test (BNT; Kaplan, Goodglass, \& Weintraub, 1983), we have found that more than $40 \%$ of patients with chronic progressive MS, and nearly $20 \%$ of patients with relapsing remitting MS, exhibit dysnomia, which is only partially alleviated by cuing. In subsequent studies, we have found that MS patients with dysnomia (as defined by performance on the BNT) exhibit

\footnotetext{
We thank David P. Salmon for providing the materials for the semantic priming test and for his helpful comments on an earlier version of the manuscript, Donald E. Goodkin for allowing us to test his patients, and especially the patients who participated in the study. Please address all correspondence and reprint requests to William W. Beatty, Clinical Neuroscience Research Program, Neuropsychiatric Research Institute, P.O. Box 1415, Fargo, ND 58107.
}

a broad spectrum of deficits in access to lexical and semantic information. These deficits include reduced accuracy and increased latency to name familiar target words regardless of whether the targets were elicited by semantic, visual, or rhyming cues (Beatty \& Monson, 1989); low Wechsler Adult Intelligence Scale-Revised vocabulary scores (Beatty \& Monson, 1989); and inefficient searches of their semantic memories on a version of the supermarket fluency test (Beatty, Monson, \& Goodkin, 1989).

Although these findings demonstrate the generality of the naming-impaired patients' difficulties in accessing lexical knowledge, the reasons for their impairment remain unclear. All of the tests described above require an active and systematic search of semantic memory, and, in addition, fluency tests are highly effortful and place a premium on rapid responding. Hence, these task features, rather than a more general breakdown in the structure of semantic memory, might be responsible for the patients' poor performance.

Priming paradigms allow patients to display semantic knowledge relatively "automatically" by minimizing the requirements for active processing. Stem-completion priming requires production of words on the basis of orthographic or other lexical cues, whereas semantic priming demands production of words that are related in meaning. Previous studies of alcoholic Korsakoff patients have revealed normal performance on both lexical and semantic priming tests (Salmon, Shimamura, Butters, \& Smith, 1988; Schacter, 1985; Shimamura, Salmon, Squire, \& Butters, 1987), while mildly and moderately demented patients with Alzheimer's disease (AD) show little or no evidence of either lexical or semantic priming (Salmon et al., 1988; Shimamura et al., 1987). Patients with Huntington's disease (HD) perform normally on lexical 
priming tests (Salmon et al., 1988; Shimamura et al., 1987), but show diminished sensitivity to the influence of association strength on a semantic priming task (Smith, Butters, White, Lyon, \& Granholm, 1988). This latter effect was particularly evident among moderately (as opposed to mildly) demented HD patients who also evidenced dysnomia on the BNT. Smith et al. interpreted the reduced impact of association strength on semantic priming by HD patients as evidence for disruption in the system of spreading activation in a lexical-semantic network.

Since there are many similarities in the overall neuropsychological profiles of MS and HD patients (Caine et al., 1986; Cummings \& Benson, 1984; Rao, 1986), it might be expected that their performance on priming tests would also be similar. Consistent with this prediction, we observed normal lexical priming by MS patients regardless of whether they were normal or impaired in naming (Beatty, Goodkin, Monson, \& Beatty, in press). In the present study, we examined semantic priming by MS patients with normal or low naming ability.

\section{METHOD}

\section{Subjects}

Sixty-four subjects participated in the study: 42 patients (15 male, 27 female) who met criteria for clinically definite MS (Poser et al., 1983) and 22 neurologically intact normal controls (8 males, 14 female). On the basis of their regular neurological examination closest in time to the present tests, 18 patients carried the diagnosis of chronic progressive MS and 9 patients carried the diagnosis of relapsing remitting MS. Operational definitions of these disease types are reported elsewhere (Beatty, Goodkin, Monson, \& Beatty, 1989). Fifteen patients had shown no significant change in neurological status during the 2 years preceding this study, and were considered to have a stable disease course. $\mathrm{Pa}$ tients and controls with histories of alcohol or drug abuse, learning disabilities, major psychiatric illness, recent or complicated heart attacks, metabolic diseases, uncontrolled hypertension, or neurological diseases (other than MS for the patients) were excluded.

Level of disability (for the patients only) was assessed at the time of neuropsychological testing using the ambulation index (AI; Hauser et al., 1983). In a study of 85 MS patients, we (Beatty, Goodkin, Hertsgaard, \& Monson, 1990) found that scores on the AI and the expanded disability status scale (Kurtzke, 1983) were very highly correlated $(r=.96)$.

\section{Materials and Procedure}

As a measure of overall cognitive function, we administered the screening examination for cognitive impairment in multiple sclerosis (SECIMS). The SECIMS was developed because the Mini-Mental State Exam (MMSE; Folstein, Folstein, \& McHugh, 1975), which we have used in previous studies, has proved insensitive to cognitive impairment in MS patients (Beatty \& Goodkin, 1990). The SECIMS is identical to the MMSE, except that the number of words to be recalled immediately and after delay is increased to seven and the two naming items (pencil, watch) are replaced by a 15 -item version of the BNT, which is known to be highly correlated with the 60 -item version of the test and is equally sensitive for detecting dysnomia in $\mathrm{AD}$ patients (Mack, Henderson, \& Freed, 1988).

Maximum score on the SECIMS is 51. A sample of 52 normal controls, who were closely matched in age ( $M=42.9$ years) and education ( $M=14.2$ years) to the MS patients served by our clinic, averaged $48.3 \pm 1.6$ on the SECIMS and $14.2 \pm 1.0$ on the 15 naming items. If the fifth percentile is used to define impairment, then the cutoff scores for impairment are below 46 for the entire SECIMS and below 13 for the naming items. These operational definitions were employed in the present study.
On the letter-fluency (FAS) test, the subjects were asked to name as many different words as possible that began with the letters F, A, and S. Sixty seconds were allowed for each letter, and proper names were not permitted.

The stimulus materials for the semantic priming task were identical to those used by Salmon et al. (1988) and Smith et al. (1988) and are described in detail in their reports. In brief, 48 stimulus words were paired with two response words: one a strong associate (rank order 1-3), the other a moderate associate (rank order 8-11). Half of the resulting 96 associates were "functional pairs" (e.g., NEEDLE-THREAD) and half were "categorical pairs" (e.g., BIRD-ROBIN). Six additional word pairs with no apparent semantic relationship (i.e., "unrelated pairs") were used to control for the possibility that the subjects might respond to stimulus words during the free-association phase simply because the words had been paired together, not because an existing semantic association had been primed. Word pairs were printed individually on $10.2 \times 15.4 \mathrm{~cm}$ cards for presentation to the subjects during the rating phase of the test. Stimulus words were printed individually on similar cards for presentation during the free-association phase of the task.

The test was administered in three identical blocks; each block was composed of a rating task and a free-association task. On the rating task, the subjects were shown cards containing pairs of words, which they rated on a 5-point scale $(1=$ not at all related, $5=$ very closely related $)$. The scale was printed on a $10.2 \times 15.4 \mathrm{~cm}$ card, which remained in the subject's view at all times. Each block comprised four strong associates, four moderate associates, two unrelated word pairs, and two fillers. Filler pairs were presented first and last in the series of 12 word pairs.

Immediately after completing the ratings for each block, the freeassociation task was presented. The subjects were shown cards on which either the first word of a pair seen in the rating task or a distractor word (one that the subject had not seen during the rating task) was printed. They were asked to say "the first word that comes to mind" in response to each stimulus word, and the examiner never mentioned that the freeassociation task was related to the previous rating task. In each block, 10 stimulus words and $\mathbf{8}$ distractors were presented in a random order. Inclusion of the distractors provided a baseline that allowed an estimation of the probability of a correct response due solely to chance. The use of word pairs as targets or distractors was counterbalanced between subjects.

The subjects responded orally and the examiner recorded their responses. The same procedures were followed for the second and third blocks.

A preliminary analysis indicated that there were no significant differences between categorical and functional pairs; therefore, the data were collapsed across this variable.

\section{RESULTS}

Table 1 summarizes the demographic, clinical, and psychometric data for the MS patients and the normal controls. A preliminary analysis showed that the MS patients with low naming ability also attained lower overall scores on the SECIMS than the patients of normal naming ability. Hence, any differences among groups on the semantic priming task might be due to differences in overall cognitive function. To evaluate this possibility, a third group of patients (the low-SECIMS group) was formed. These patients scored below 46 on the SECIMS, but their naming scores were within the normal range (BNT: 13-15).

The resulting four groups (i.e., normal controls and the three patient subgroups) did not differ significantly in terms of age $(F<1)$ or education $[F(3,61)=2.27$, $p>$.05]. Patient groups with low SECIMS scores tended to be somewhat more physically disabled than the patients with normal SECIMS scores, but these differences were 
Table 1

Demographic, Clinical, and Psychometric Characteristics of Multiple Sclerosis (MS) Patients and Control Subjects

\begin{tabular}{|c|c|c|c|c|c|c|c|c|}
\hline & \multicolumn{8}{|c|}{ Subjects } \\
\hline & \multicolumn{2}{|c|}{$\begin{array}{l}\text { Controls } \\
(n=22)\end{array}$} & \multicolumn{2}{|c|}{$\begin{array}{l}\text { MS-Normal } \\
\text { BNT and } \\
\text { SECIMS } \\
(n=25)\end{array}$} & \multicolumn{2}{|c|}{$\begin{array}{c}\text { MS-Low } \\
\text { SECIMS } \\
\text { and BNT } \\
(n=7)\end{array}$} & \multicolumn{2}{|c|}{$\begin{array}{c}\text { MS-Low } \\
\text { SECIMS } \\
\text { Normal BNT } \\
(n=10)\end{array}$} \\
\hline & $M$ & $S D$ & $M$ & $S D$ & $M$ & $S D$ & $M$ & $S D$ \\
\hline Age (years) & 49.0 & 16.7 & 46.3 & 13.2 & 51.3 & 9.8 & 43.3 & 7.2 \\
\hline Education (years) & 14.3 & 2.0 & 14.5 & 2.3 & 12.1 & 2.2 & 13.7 & 2.2 \\
\hline Ambulation Index & & & 3.6 & 2.7 & 5.7 & 3.2 & 4.7 & 3.7 \\
\hline $\begin{array}{c}\text { Disease Type } \\
\text { CP/RR/S }\end{array}$ & & & \multicolumn{2}{|c|}{$7 / 6 / 12$} & \multicolumn{2}{|c|}{$6 / 0 / 1$} & $5 / 3 / 2$ & \\
\hline SECIMS & 48.7 & 1.4 & 48.1 & 1.5 & 40.6 & 1.6 & 42.2 & 2.7 \\
\hline BNT & 14.5 & 0.8 & 14.7 & 0.5 & 11.3 & 0.5 & 13.6 & 0.7 \\
\hline FAS & 44.9 & 11.8 & 35.8 & 11.3 & 22.4 & 7.0 & 23.4 & 9.7 \\
\hline
\end{tabular}

Note-BNT = Boston Naming Test, SECIMS = screening examination for cognitive impairment in multiple sclerosis, $\mathrm{CP} / \mathrm{RR} / \mathrm{S}=$ chronic progressive/relapsing remitting/stable, SECIMS = screening examination for cognitive impairment in multiple sclerosis, FAS = letter-fluency test.

not significant $(F=1.58)$. Likewise, there was no significant difference among groups in the proportion of patients of different diagnostic types $\left[\chi^{2}(4)=8.10\right.$, $p>$.05]. All of the MS patient groups produced fewer correct words on the FAS test than did the controls $(p s<.01)$. Patients who performed normally on the BNT and the SECIMS produced more correct words on the FAS test than did the patients in the other two groups $(p s<.01)$.

Despite differences in naming ability and overall level of cognitive functioning, all of the MS patient groups performed normally on the semantic priming task (see Table 2). Statistical analysis of the overall priming score revealed no difference among groups $(F<1)$. The same pattern of highly similar performance by all groups was evident when net priming scores (the difference between the primed and baseline conditions) were considered separately for strongly and moderately associated pairs $(F \mathrm{~s}<1)$. The percentage of hits for previously presented but unrelated pairs was low for all groups $(F<1)$, which indicates that nearly all of the subjects treated the task as one of free association rather than as a test of explicit recall.

\section{DISCUSSION}

Like patients with HD (Salmon et al., 1988), the MS patients tested in the present study exhibited normal overall levels of semantic priming. Whereas the impact of associative strength on priming is less for HD patients than for controls (Smith et al., 1988), no such trend was evident among the MS patients we studied, even in the patient groups with low BNT scores or impaired mental status without naming deficits. In other work with MS patients, we have observed normal performance on tests of lexical priming (Beatty, Goodkin, Monson, \& Beatty, in press) and on release from proactive interference after a categorical shift in the to-be-remembered stimuli (Beatty, Goodkin, Beatty, \& Monson, 1989).

Taken together, these observations indicate that the structure of semantic memory remains intact in MS. This suggests that the mild impairments in confrontational naming, as well as the more severe impairments on verbal fluency tests exhibited by many MS patients, are examples of a general difficulty in retrieval of established verbal knowledge (Beatty

Table 2

Percentage of Primed Target Hits for Multiple Sclerosis (MS) Patients and Control Subjects

\begin{tabular}{|c|c|c|c|c|c|c|c|c|}
\hline & \multicolumn{8}{|c|}{ Subjects } \\
\hline & \multicolumn{2}{|c|}{ Controls } & \multicolumn{2}{|c|}{$\begin{array}{l}\text { MS-Normal } \\
\text { BNT and } \\
\text { SECIMS } \\
\end{array}$} & \multicolumn{2}{|c|}{$\begin{array}{l}\text { MS-Low } \\
\text { SECIMS } \\
\text { and BNT }\end{array}$} & \multicolumn{2}{|c|}{$\begin{array}{c}\text { MS-Low } \\
\text { SECIMS } \\
\text { Normal BNT }\end{array}$} \\
\hline & $M$ & $S D$ & $M$ & $S D$ & $M$ & $S D$ & $M$ & $S D$ \\
\hline \multicolumn{9}{|c|}{ Strong Associates } \\
\hline Primed & 46.6 & 24.9 & 58.3 & 19.7 & 52.4 & 16.5 & 43.3 & 20.0 \\
\hline Baseline & 24.6 & 11.9 & 25.3 & 14.5 & 28.6 & 10.6 & 15.8 & 14.9 \\
\hline Net & 22.0 & 27.3 & 33.0 & 22.4 & 23.8 & 14.0 & 27.5 & 22.2 \\
\hline \multicolumn{9}{|c|}{ Moderate Associates } \\
\hline Primed & 18.6 & 18.4 & 19.3 & 21.1 & 11.9 & 11.6 & 11.7 & 9.8 \\
\hline Baseline & 0.4 & 1.8 & 1.3 & 3.1 & 3.6 & 4.5 & 0.8 & 2.6 \\
\hline Net & 18.2 & 18.8 & 18.0 & 21.6 & 8.3 & 12.7 & 10.8 & 8.8 \\
\hline Overall Priming Score & 20.1 & 20.1 & 25.5 & 19.0 & 16.1 & 12.1 & 19.2 & 13.6 \\
\hline Unrelated Pairs & 8.3 & 14.3 & 4.7 & 9.0 & 2.4 & 6.3 & 3.3 & 7.0 \\
\hline
\end{tabular}

Note-BNT = Boston Naming Test, SECIMS = screening examination for cognitive impairment in multiple sclerosis. 
\& Monson, 1989; Beatty, Monson, \& Goodkin, 1989). Because MS patients process information slowly (Beatty et al., 1988; Litvan et al., 1988; Rao et al., 1989), this postulated retrieval deficit is more easily demonstrated if the task places a premium on rapid responding.

The possible clinical significance of the low scores on the BNT attained by some patients has yet to be addressed. Although their BNT and fluency scores are often as low as those of mildly or moderately demented AD patients, MS patients do not typically exhibit the wordfinding difficulties and circumlocutions that are often evident in the everyday speech of AD patients. Our research on lexical and semantic priming in MS supports the conclusions from clinical observations-namely, that the nature of the dysnomias in MS and AD is quite different. However, a subtle disturbance in word finding by MS patients with low BNT scores, as might be evident if they were asked to describe a complex but well-known activity (e.g., wrapping a package), cannot be ruled out.

\section{REFERENCES}

Beatty, W. W., \& Goodkin, D. E. (1990). Screening for cognitive impairment in multiple sclerosis: An evaluation of the Mini-Mental State Exam. Archives of Neurology, 47, 297-301.

Beatty, W. W., Goodkin, D. E., Beatty, P. A., \& Monson, N. (1989). Frontal lobe dysfunction and memory impairment in patients with chronic progressive multiple sclerosis. Brain \& Cognition, 11, 73-86.

Beatty, W. W., Goodkin, D. E., Hertsgaard, D., \& Monson, N. (1990). Clinical and demographic predictors of cognitive performance in multiple sclerosis: Do diagnostic type, disease duration and disability matter? Archives of Neurology, 47, 305-308.

Beatty, W. W., Goodkin, D. E., Monson, N., \& Beatty, P. A. (1989). Cognitive disturbances in patients with relapsing remitting multiple sclerosis. Archives of Neurology, 46, 1113-1119.

Beatty, W. W., Goodkin, D. E., Monson, N., \& Beatty, P. A. (in press). Implicit learning in patients with chronic progressive multiple sclerosis. International Journal of Clinical Neuropsychology.

Beatty, W. W., Goodkin, D. E., Monson, N., Beatty, P. A., \& HERTSGAARD, D. (1988). Anterograde and retrograde amnesia in patients with chronic progressive multiple sclerosis. Archives of Neurology, 45, 611-619.

Beatty, W. W., \& Monson, N. (1989). Lexical processing in Parkinson's disease and multiple sclerosis. Journal of Geriatric Psychiatry \& Neurology, 2, 151-158.

Beatty, W. W., Monson, N., \& Goodkin, D. E. (1989). Access to semantic memory in Parkinson's disease and multiple sclerosis. Journal of Geriatric Psychiatry \& Neurology, 2, 159-168.

Caine, E. D., Bamford, K. A., Schiffer, R. B., Shoulson, I., \& LEVY, S. (1986). A controlled neuropsychological comparison of Huntington's disease and multiple sclerosis. Archives of Neurology, 43, 249-254.
Cummings, J. L., \& Benson, D. F. (1984). Subcortical dementia: Review of an emerging concept. Archives of Neurology, 41, 871-879.

Folstein, M. F., Folstein, S. E., \& McHugh, P. R. (1975). “MiniMental State': A practical method for grading the cognitive state of patients for the clinician. Journal of Psychiatric Research, 12, 189-198.

hauser, S. L., Dawson, D. M., Lehrich, J. R., Beal, M. F., Kevy, S. V., Propper, R. D., Mills, J. A., \& Weiner, H. L. (1983). Intensive immunosuppression in multiple sclerosis. New England Journal of Medicine, 308, 173-180.

Kaplan, E., Goodglass, H., \& Weintraub, S. (1983). Boston Naming Test. Philadelphia: Lea \& Febiger.

KURTZKE, J. F. (1983). Rating neurological impairment in multiple sclerosis: An expanded disability status scale (EDSS). Neurology, 33, 1444-1452.

Litvan, I., Grafman, J., Vendrell, P., \& Martinez, J. M. (1988). Slowed information processing in multiple sclerosis. Archives of Neurology, 45, 281-285.

Mack, W., Henderson, V. H., \& Freed, D. (1988, April). Boston Naming Test: Shortened versions for use in Alzheimer's diease. Paper presented at the Annual Meeting of the American Academy of Neurology, Cincinnati.

Poser, C. M., Paty, D. W., Scheinberg, L., McDonald, W. I., Davis, F., Ebers, G. C., Johnson, K. P., Sibley, W. A., Silberberg, D. H., \& Tourtellotte, W. W. (1983). New diagnostic criteria for multiple sclerosis: Guidelines for research protocols. Annals of Neurology, 13, 227-231.

RAO, S. M. (1986). Neuropsychology of multiple sclerosis: A critical review. Journal of Clinical \& Experimental Neuropsychology, 8, 503-542.

Rao, S. M., St. Aubin-Faubert, P., \& Leo, G. J. (1989). Information processing speed in multiple sclerosis. Journal of Clinical \& Experimental Neuropsychology, 11, 471-477.

Salmon, D. P., Shimamura, A. P., Butters, N., \& Smith, S. (1988). Lexical and semantic priming deficits in patients with Alzheimer's disease. Journal of Clinical \& Experimental Neuropsychology, 10, 477-494.

Schacter, D. L. (1985). Priming of old and new knowledge in amnesic patients and normal subjects. Annals of the New York Academy of Sciences, 444, 41-53.

Shimamura, A. P., Salmon, D. P., Squire, L. R., \& Butters, N. (1987). Memory dysfunction and word priming in dementia and amnesia. Behavioral Neuroscience, 101, 347-351.

Smith, S., Butters, N., White, R., Lyon, L., \& Granholm, E. (1988). Priming semantic relations in patients with Huntington's disease. Brain \& Language, 33, 27-40.

(Manuscript received January 13, 1990.) 